\title{
ANALISA KERUSAKAN SUDU TURBIN GAS MATERIAL UDIMET 500 KAPASITAS 50 MW
}

\author{
Tarmizi \\ Balai Besar Logam dan Mesin Bandung
}

\begin{abstract}
Abstrak
Penelitian Kerusakan pada Sudu Turbin Gas Kapasitas 50 MW yang dibuat dari material Udimet 500 atau Waspalloy telah dilakukan. Tujuan penelitian adalah mengetahui penyebab kerusakan agar kejadian serupa tidak terulang kembali. Untuk mengetahui penyebabnya beberapa metoda yang dilakukan adalah: (1) pemeriksaan visual (2) pemeriksaan mikro menggunakan dan Scanning Electron Micsroscope (3) pengujian komposisi kimia. Hasil penelitian membuktikan bahwa penyebab kegagalan pada sudu turbin karena penurunan karakteristik material akibat terekspos pada temperatur tinggi diatas $632{ }^{\circ} \mathrm{C}$ dalam waktu yang lama sehingga material sudu terjadi penuaan, hal ini bisa dilihat dari adanya presipitasi senyawa yang sudah terbentuk disepanjang batas butir.
\end{abstract}

Kata kunci : sudu turbin, presipitasi senyawa, korosi.

\begin{abstract}
A research of Failure Analysis of Blade Turbine, Capacity $50 \mathrm{MW}$ has been conducted. Material of blade is Udimet 500 or Waspalloy. Testing was started with visual inspection, collecting of metallography speciment and Scanning Electron Micsroscopy and then continued with material chemical composition test of blade with of X-Ray fluorescent method and corrosion product found on turbine blade with method of Energy Dispertion Spectrography. The result of the research conducted on turbine blade shows that the failure on turbine blade is caused by degradation of material characteristic which is exposed at high temperature for a long duration so that the material of blade becomes aged, it can be seen from the existence of compound precipitation which have been formed alongside boundary.
\end{abstract}

Keywords : Turbine Blade, Compound Precipitation, Corrosion.

\section{PENDAHULUAN}

Kebutuhan energi listrik saat ini sudah sangat penting seiring dengan perkembangan industri yang semakin pesat. Kebutuhan energi listrik tiap tahun mengalami peningkatan yang sangat pesat sementara dilain pihak unit-unit pembangkit yang ada hampir tidak mengalami peningkatan yang signifikan bahkan dibeberapa unit pembangkit ada yang mengalami krisis pasokan bahan bakar baik berupa gas, batubara maupun bahan bakar minyak. Bahkan sering terjadi pemadaman bergilir akibat kekurangan kapasitas listrik yang dibutuhkan oleh masyarakat sehingga menghambat proses produksi di beberapa industri dan fasilitas lalu lintas yang mengakibatkan kemacetan. Salah satu penyebab kurangnya pasokan energi listrik tersebut adanya kerusakan beberapa unit pembangkit di daerah sehingga pasokan listrik jadi berkurang.

Penelitian yang dilakukan tujuannya adalah untuk mengetahui penyebab terjadinya kegagalan atau kerusakan sudu turbin sehingga kejadian serupa tidak terjadi kembali. Kajian ini dilakukan dengan mengacu pada data operasi, gambargambar turbin beserta sudu-sudunya serta informasi yang didapat dilapangan. Berdasarkan informasi yang didapat dilapangan, tanda-tanda kegagalan dicirikan oleh adanya excessive vibration yang menyebabkan turbin trip.

Kerusakan sudu dapat terjadi oleh adanya sejumlah mekanisme dibawah kondisi operasi turbin pada kecepatan 
putaran tinggi pada temperatur tinggi. Pada umumnya umumnya kerusakan sudu dapat dikelompokkan menjadi dua bagian yaitu a. Fatique, kelelahan termasuk pada high cycle fatique (HCF) atau low cucle fatique (LCF) b. Creep Rupture, mulur akibat dari temperatur operasi yang melebihi temperatur rekristalisasi material sudu.

Untuk mengetahui penyebabnya, perlu dilakukan pemeriksaan dan pengujian apakah hal tersebut disebabkan oleh misallignment atau permasalahan toleransi atau spall off pada bantalan atau adanya kondisi operasi yang tidak sesuai dengan kondisi operasi yang dipersyaratkan oleh material sudu turbin tersebut. Hasil pemeriksaan dan pengujian akan mendukung analisis dari kerusakan tersebut.

\section{Prinsip Kerja Turbin}

Turbin adalah pesawat penggerak dimana gerak putar yang terjadi diperoleh dari hasil konversi energi dari energi potensial diubah menjadi energi kinetik pada nozzle dan diteruskan menjadi energi mekanik pada sudu yang memutar poros sebagai penggerak generator untuk menghasilkan energi listrik. Bahan bakar gas yang dialirkan melalui pipa-pipa gas yang disalurkan melalui nozzle keruang bakar dengan kecepatan dan tekanan tertentu yang akan menggerakkan turbin disc yang dipasang pada rotor seperti terlihat pada gambar 1, sehingga menimbulkan energi mekanik pada poros yang akan menghasilkan gerak putar untuk menggerakkan generator dan menghasilkan energi listrik. Temperatur operasi diruang bakar $500{ }^{\circ} \mathrm{C}$ yang dikontrol melalui termokopel yang dipasang pada ruang bakar, untuk menjaga supaya sudu tidak mengalami temperatur operasi yang berlebih maka dipakai sistim pendinginan sudu dengan metoda "fogging" yang dipasang pada turbin gas tersebut.



Gambar 1 : Rotor dari turbin gas

\section{METODA PENELITIAN}

Dalam penelitian ini dilakukan serangkaian pemeriksaan dan pengujian seperti yang ditampilkan pada Gambar 2, yang dimulai dengan melakukan Pengamatan visual pada sudu yang mengalami kerusakan kemudian dilanjutkan dengan pengambilan sample sudu dan produk korosi. Kemudian dilakukan pengamatan metalografi dengan mikroskop optik dan SEM pada material sudu yang mengalami kerusakan. Sampel sudu dengan ukuran $20 \times 20 \mathrm{~mm}$ dilakukan pemeriksaan komposisi kimia dan serbuk produk korosi menggunakan EDXS.

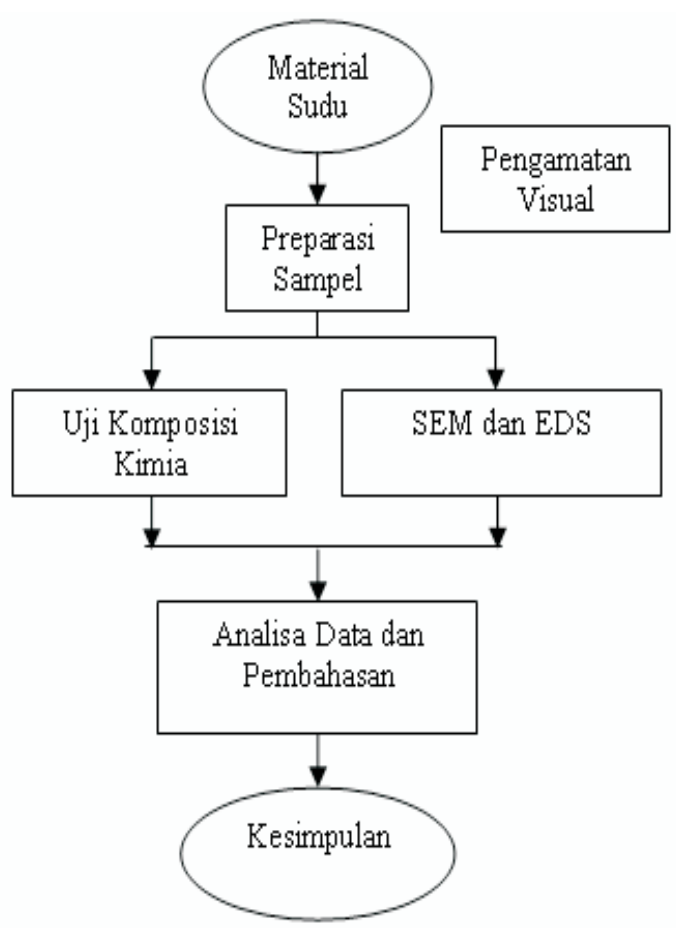

Gambar 2 : Diagram Alir Penelitian

\section{HASIL DAN PEMBAHASAN}

Dari hasil uji yang telah dilakukan didapatkan data-data sebagai berikut :

\section{Pengamatan Visual}

Dari hasil pemeriksaan visual yang telah dilakukan dapat dilihat pada Gambar 3 dan 4. 



Gambar 4 : Pengecilan di daerah ujung menandai adanya penomena Creep

Hasil pemeriksan visual seperti terlihat pada Gambar 3 dan 4 diatas menunjukkan adanya kerusakan sudu yang mengalami pengecilan penampang akibat adanya fenomena creep yang terjadi pada temperatur tinggi (seperti yang ditunjukkan pada gambar 5 dari ASM Handbook Vol.11, 2002), biasanya sedikit diatas temperatur rekristalisasi dari material sudu. Fenomena creep tersebut disebabkan adanya thermal load cyclic. Komponen yang mengalami beban creep ini lambat laun akan mengalami kegagalan jikalau regangan (strain) yang timbul selama proses creep tidak bisa menghilangkan tegangan (stress) yang ditimbulkannya. Hasil pemeriksaan komposisi kimia sudu turbin menggunakan Energy Dispersive X-Ray Spectroscopy seperti pada Gambar 6, terlihat bahwa kandungan unsur tertinggi adalah $\mathrm{Ni}$, kemudian diikuti $\mathrm{Cr}$, Co, Fe, Mo dan Ti maka material tersebut diperkirakan termasuk material U500 atau Waspalloy sesuai dengan spesifikasi bahan sudu turbin gas yang dipersyaratkan.

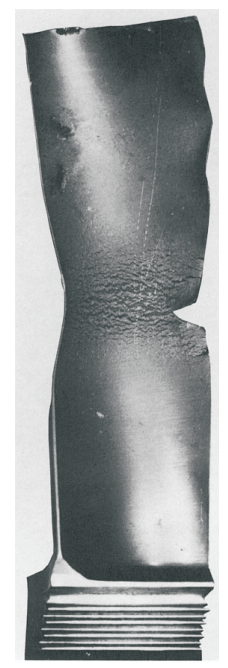

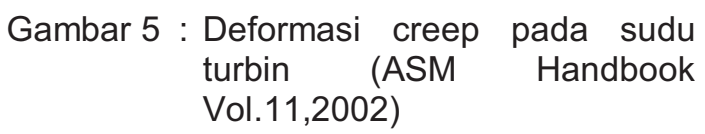



Gambar 6 : Hasil uji EDAX material sudu

Sedangkan kekuatan mekanik dari bahan sudu ini sesuai referensi dari ASM Handbook (Propertiesand Selection: Irons, Steels, and High Performance Alloys, ASM Handbook, Volume I, 2005) seperti ditunjukkan pada Tabel 1.

Tabel 1. Rupture strength material waspalloy/Udimet 500

\begin{tabular}{|c|c|}
\hline $\begin{array}{c}\text { Temperatur } \\
\left({ }^{\circ} \mathrm{C}\right)\end{array}$ & $\begin{array}{c}\text { Rupture strength, } \\
\mathrm{MPa}(\mathrm{ksi})\end{array}$ \\
\hline 650 & $760(110)$ \\
\hline 760 & $325(47)$ \\
\hline 870 & $125(18)$ \\
\hline 980 & tidak terdeteksi \\
\hline
\end{tabular}


Fenomena creep terjadi pada temperatur sedikit diatas temperatur rekristalisasi. Untuk material sudu Udimet 500 atau Waspalloy, temperatur tersebut adalah $632{ }^{\circ} \mathrm{C}$. Padahal pembacaan pada termokopel yang terpasang adalah sekitar $500{ }^{\circ} \mathrm{C}$. Jadi perlu diperiksa apakah termokopelnya sudah terkalibrasi atau belum.

Seandainya tidak ada masalah dengan termokopel, perlu dicek apakah "penyemprotan" proses fogging berdampak pada ketepatan penunjukkan temperatur operasi sudu. Karena apabila efek fogging yang bertujuan "mendinginkan" sudu malah diterjemahkan oleh termokopel sebagai penurunan temperatur operasi, maka termokopel akan "memerintahkan" system pembakaran untuk mensuplai fluida kerja yang berdampak pada peningkatan temperatur operasi. Apabila temperatur operasi mencapai $632{ }^{\circ} \mathrm{C}$ atau lebih maka sudu akan mengalami overheating.

Rangkaian Gambar 7, 8 dan 9 menunjukkan adanya tanda-tanda sudu terkorosi. Dari Gambar 7 korosi terjadi pada daerah srout atau pada poros turbin, Gambar 8 dan 9 tampak pada ujung sudu berwarna putih ini menunjukkan adanya fenomena korosi pada bagian ujung sudu tersebut. Dari analisis terhadap fluida kerja, sangat tidak mungkin menghasilkan oksidasi yang sangat excessive. Kemungkinan besar oksidasi ini timbul karena efek fogging.

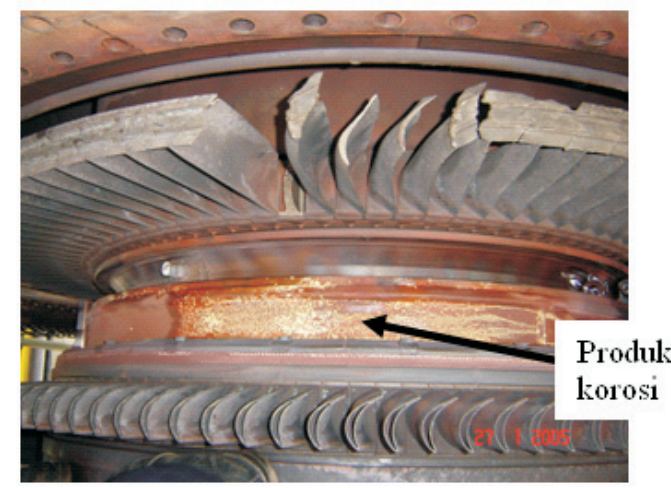

Gambar 7 : Produk korosi yang terdapat pada srout.

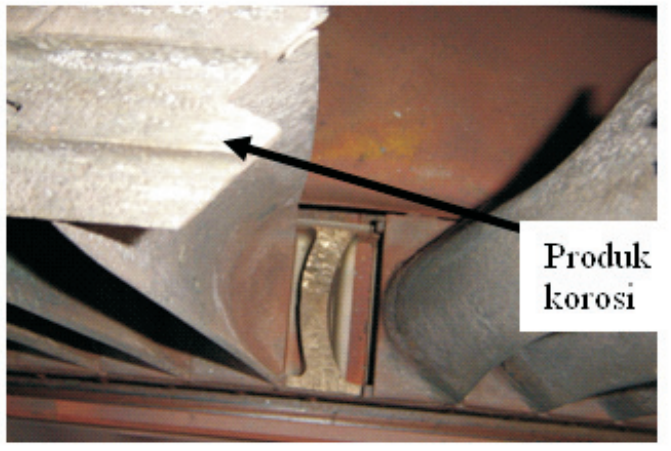

Gambar 8 : Produk korosi pada sudu turbin

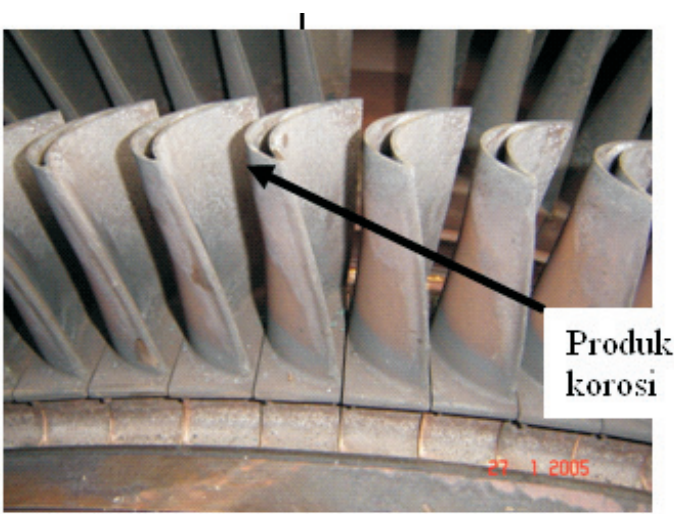

Gambar 9 : Produk korosi pada sudu turbin

Hasil analisa yang dilakukan terhadap produk korosi sudu turbin menggunakan Energy Dispersive X-Ray Spectroscopy yang diambil dari bagian seperti ditunjukkan pada Gambar 7, 8 dan 9 menunjukkan bahwa produk korosi seperti ditunjukkan pada Gambar 10 terlihat bahwa kandungan unsur tertinggi adalah $\mathrm{Fe}$, kemudian diikuti oleh O dan Si.

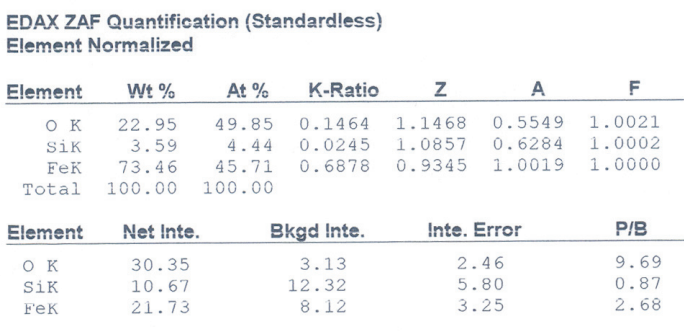

Gambar 10. Hasil uji EDXS produk korosi 


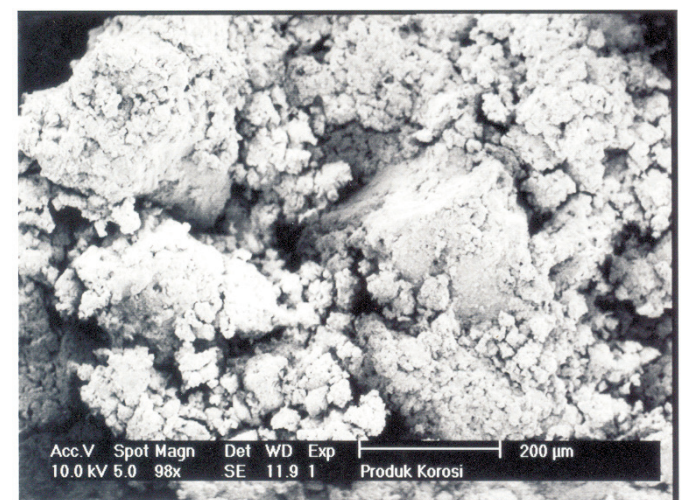

Gambar 11 : Struktur mikro produk korosi

Dari hasil analisis terhadap produk korosinya seperti pada Gambar 11, tampak bahwa produk korosi berupa oksida besi. Ini dapat diidentifikasikan bahwa excessive fogging berdampak pada timbulnya oksidasi. Hal ini bisa terjadi karena adanya kebocoran pada skid pump ataupun saluran sistem fogging yang mengakibatkan air terbawa masuk kedalam turbin. Fenomena seperti ini memang menjadi perhatian penting bagi sistem fogging seperti yang banyak dikemukakan oleh para pembuat dan pemakai sistem fogging ini. Fenomena korosi ini terjadi karena adanya reaksi elektrokimia antara logam dengan aqueous environment yang menyebabkan adanya reaksi seperti berikut ini:

$$
\begin{aligned}
& \text { Oksidasi } \mathrm{Fe} \longrightarrow \mathrm{Fe}^{2+}+\mathrm{H}_{2} \\
& \text { Reduksi } \mathrm{O}_{2}+4 \mathrm{H}^{+}+4 \mathrm{e}^{-} \longrightarrow 2 \mathrm{H}_{2} \mathrm{O}
\end{aligned}
$$

Reaksi keseluruhan:

$$
2 \mathrm{Fe}+\mathrm{O}_{2}+4 \mathrm{H}^{+} \longrightarrow 2 \mathrm{Fe}^{2+}+2 \mathrm{H}_{2} \mathrm{O}
$$

Adanya scale pada sudu turbin akan mengakibatkan terhambatnya perpindahan panas sehingga mengakibatkan timbulnya overheating.

Pada Gambar 12 terlihat permukaan patahan sudu menunjukkan fenomena patah getas.

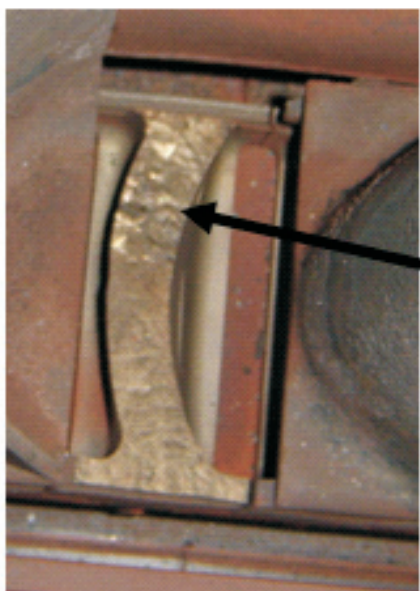

\section{Fenomena patah getas}

Gambar 12 : Permukaan

patahan menunjukkan fenomena patah getas

Dari permukaan patahan sudu seperti pada Gambar 12, terlihat bahwa patahannya getas (brittle) yang tidak menunjukkan adanya deformasi plastis pada permukaan patahan. Selain itu sudu turbin tersebut berwarna hitam seperti terbakar yang menandakan adanya proses pemanasan berlebih (overheating). Berdasarkan referensi dari ASM handbook (Failure Analysisis and Prevention, Volume 11, 1986) dinyatakan bahwa kekuatan mekanik suatu bahan nickel-base and cobalt-base high temperature alloys menjadi sangat terbatas pada temperatur $0.56 \mathrm{Tm}$ (temperatur cair absolut). Pada temperatur $0.56 \mathrm{Tm}$ ini, sudu mengalami fenomena elevated-temperatur behaviour yang ditandai oleh adanya creep.

Dari data operasi yang ada, pembacaan termokopel pada turbin adalah sekitar $500{ }^{\circ} \mathrm{C}$. Sedangkan material sudu adalah $U 500$ atau waspalloy yang memiliki temperatur cair $(\mathrm{Tm})$ sebesar $2475{ }^{0} \mathrm{~F}$ atau $1343{ }^{0} \mathrm{C}$. Jadi elevated temperature behaviour untuk bahan sudu turbin ini akan dimulai pada temperatur $905 \mathrm{~K}$ atau $632{ }^{\circ} \mathrm{C}$. Hasil uji scanning electron microscopy pada material sudu seperti yang ditunjukkan pada Gambar 13. 


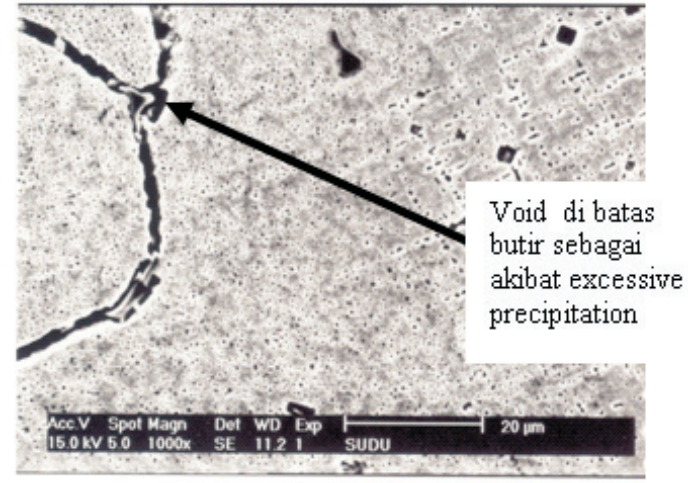

Gambar 13 : Struktur mikro sudu turbin

Berdasarkan Gambar 11 struktur mikro diatas, terlihat adanya fenomena grain growth dan excessive precipitation yang menyebabkan adanya void diantara batas butir. Sesuai dengan referensi dari ASM (Failure Analysis and Prevention, ASM Handbook, Volume 11, 2002) disebutkan bahwa adanya creep pada tertiary phase ditandai adanya grain-boundary sliding yang mengakibatkan adanya void atau crack. Void pada batas butir dapat juga disebabkan karena adanya excessive precipitation disepanjang batas butir. Fenomena seperti itu terjadi jika material sudu pernah mengalami exposure pada temperatur yang tinggi.

\section{KESIMPULAN}

Dari hasil pengujian yang telah dilakukan dapat ditarik kesimpulan sebagai berikut :

1. Pengujian produk korosi menunjukkan adanya oksida besi ini dapat diidentifikasikan bahwa excessive fogging berdampak pada timbulnya oksidasi. Hal ini bisa terjadi karena adanya kebocoran pada skid pump ataupun saluran sistem fogging yang mengakibatkan air terbawa masuk kedalam turbin.

2. Kegagalan pada sudu turbin karena adanya grain-boundary sliding yang mengakibatkan adanya void atau crack akibat terekspos pada temperatur diatas temperatur rekristalisasi (di atas $632{ }^{\circ} \mathrm{C}$ ) untuk jangka waktu yang lama sehingga material sudu menjadi aged, hal ini bisa dilihat dari adanya presipitasi senyawa yang sudah terbentuk disepanjang batas butir.
5. SARAN

1. Perlu dilakukan pengontrolan termokopel yang ada pada ruang bakar sehingga kondisi temperatur dapat terbaca secara akurat.

2. Perlu dilakukan kalibrasi secara berkala pada alat temperatur kontrol sehingga tidak terjadi lagi overheat pada kondisi operasi.

\section{Ucapan terima kasih}

Penulis mengucapkan terima kasih yang sebesar-besarnya kepada Bapak Prof.Dr.Ir. Rochim Suratman dan Bapak Ir.Sony Sulaksono, MBS yang banyak memberikan sumbangan pikiran dalam penyusunan materi ini.

\section{DAFTAR PUSTAKA}

1. ASM Handbook, Properties and Selection: Irons, Steels and High Performances Alloys, Volume 1, 2005.

2. ASM Handbook, Failure Analysis and Prevention, Volume 11, 2002.

3. ASM Handbook, Corrosion, Volume 13, 1987.

4. Failure Analysis of Gas Turbine Blades, Mehdi Tofighi Naeem, Seyed Ali Jazayeri, Nesa Rezamahdi, K. N. Toosi University of Technology, Proceedings of The 2008 IAJC-IJME International Conference, ISBN 978-160643-379-9.

5. Conor, P.C. "Compressor Blade High Cycle Fatigue Life-Case Study," The Technical Cooperation Program (TTCP), P-TPI, 1998.

6. Jianfu, H., Wicks, B.J., and Antoniou, R.A., "An Investigation of Fatigue Failures of Turbine Blades in a Gas Turbine by Mechanical Analysis," Engineering Failure Analysis, vol. 9, 2002, pp. 201-211.

7. www.swri.org/4org/d18/mechflu/plante ng/gasturb/failure.htm\#Metallurgical_ Examination.

8. www.swri.org/4org/d18/mechflu/plante ng/gasturb/failure.htm\#Mechanical/Th ermal_Analyses. 


\section{RIWAYAT PENULIS}

Tarmizi, lahir di Sekayu pada tanggal 30 September 1970. Menamatkan pendidikan Sarjana di Jurusan Teknik Metalurgi Universitas Achmad Yani, Bandung, 1995. Menyelesaikan pendidikan S2 di Program Studi Magister Teknik Metalurgi Universitas Indonesia tahun 2000.
Sejak tahun 1996-2000 bekerja di Seksi Penyambungan dan Pembentukan Logam BBLM sebagai Engineer, 2000-2004 di Seksi Pengujian sebagai Teknisi, 2004-2008 sebagai Kepala Laboratorium Penguji. Sejak 2008 sampai sekarang sebagai Peneliti pada Bidang Metalurgi di Seksi Permesinan dan Pengelasan, Balai Besar Logam dan Mesin Bandung. 